\title{
International Research Interdisciplinary School Meeting in Astana, Kazakhstan 18-23 September 2017: An Introduction to How Plan a Research Project
}

\author{
Oben Baysan ${ }^{1}$, Ayan Abdrakhmanov ${ }^{2}$ \\ ${ }^{1}$ Guven Hospital, Ankara, Turkey \\ ${ }^{2}$ National Research Cardiac Surgery Center, Astana Kazakhstan
}

From 2006 to now, International Research Interdisciplinary School (IRIS) previously called as The International Scientific Schools has provided necessary skills for its participants about research principles and research training, which have been usually forgotten in the curricula of continued medical education (1). IRIS students from different countries and professions enjoy working with a collaboration to acquire skills for planning their research projects. A problem-based approach focusing on the research project is always followed in an open-discussion style. Interactive communication with frequent questions and answers among IRIS students and mentors improves their appraisal about the research project. This also creates a very good opportunity for non-native English speaker students to enhance their English speaking and understanding skills. The capital city of Kazakhstan, Astana, welcomed 17 students for IRIS meeting held from September to September (7 from Kazakhstan, 5 from Slovak Republic, 3 from Kyrgyzstan, 1 from Poland and 1 from Sweden). Faculty and organization committee of IRIS in Astana included: Ljuba Bacharova, Slovakia, Jonathan Lipton, Australia, Oben Baysan, Turkey, Ayan Abdrakhmanov, Kazakhstan, Akbota Abidina, Kazakhstan, Yersin Zhunussov, Kazakhstan, Taalaibek Kudaiberdiev, Kyrgyzstan, Samuel Bell, USA, Eric Eisenstein, USA, Gulmira Kudaiberdieva and as observer Vladislav Bacharov, Slovakia.

After initial ceremony and meeting, teaching faculty members (Ljuba, Jonathan, Oben, Ayan, Akbota and Gulmira) tried to create five groups, which included participants from different cultures as possible as they could.
Each group had responsibility to find research project on which all further discussions had to be done (Table $1)$.

Problem based education in small groups is an active learning process successfully used in both undergraduate and postgraduate level (2-4). As in previous meetings, IRIS students in Astana had gained huge experience in critical thinking about their research projects by active communication between themselves and with faculty members. The presence of different cultures, education levels and professions has been overcome by respect for each other. Never-ending questions asked by students from other groups or faculty members had been used for criticizing each research project. The first day of the meeting was especially hard for participants without previous knowledge about research project planning. They were confused and a little bit frustrated in face of criticism pointing to their research projects. Fortunately, in following three days working groups were able to find solutions for their research projects by active participation from each group member.

IRIS school was ended with group presentations about final version of research projects and closing ceremony. Four days of IRIS meeting in Astana created a very close friendship among participants from various countries with different personal backgrounds.

Active communication, the eagerness to learn, respect and to be ready for helping somebody were key elements for what was done in Astana. We strongly believe that each participant in Astana obtained basic skills for how to deal with a research project and is ready to educate other candidates from all over the world in further IRIS meetings.

Address for Correspondence: Oben Baysan, Guven Hospital, Ankara, Turkey Email: obbaysan@gmail.com

Received: 6.11.2017 Accepted: 6.11.2017 Copyright@ 2017 Heart Vessels and Transplantation 


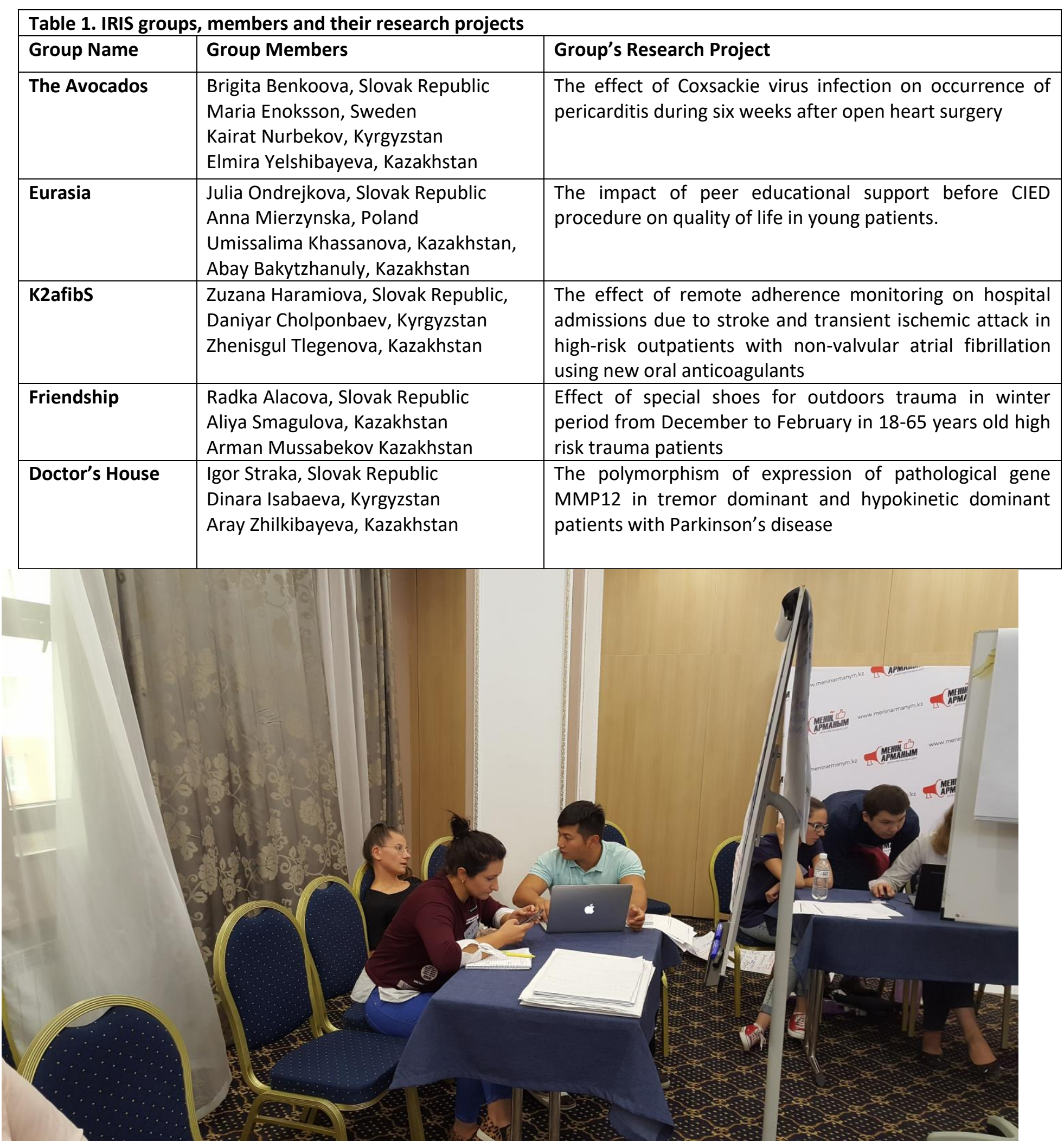

Figure 1. Group The Avocados - storming cool: Brigita Benkoova, Maria Enoksson and Kairat Nurbekov 


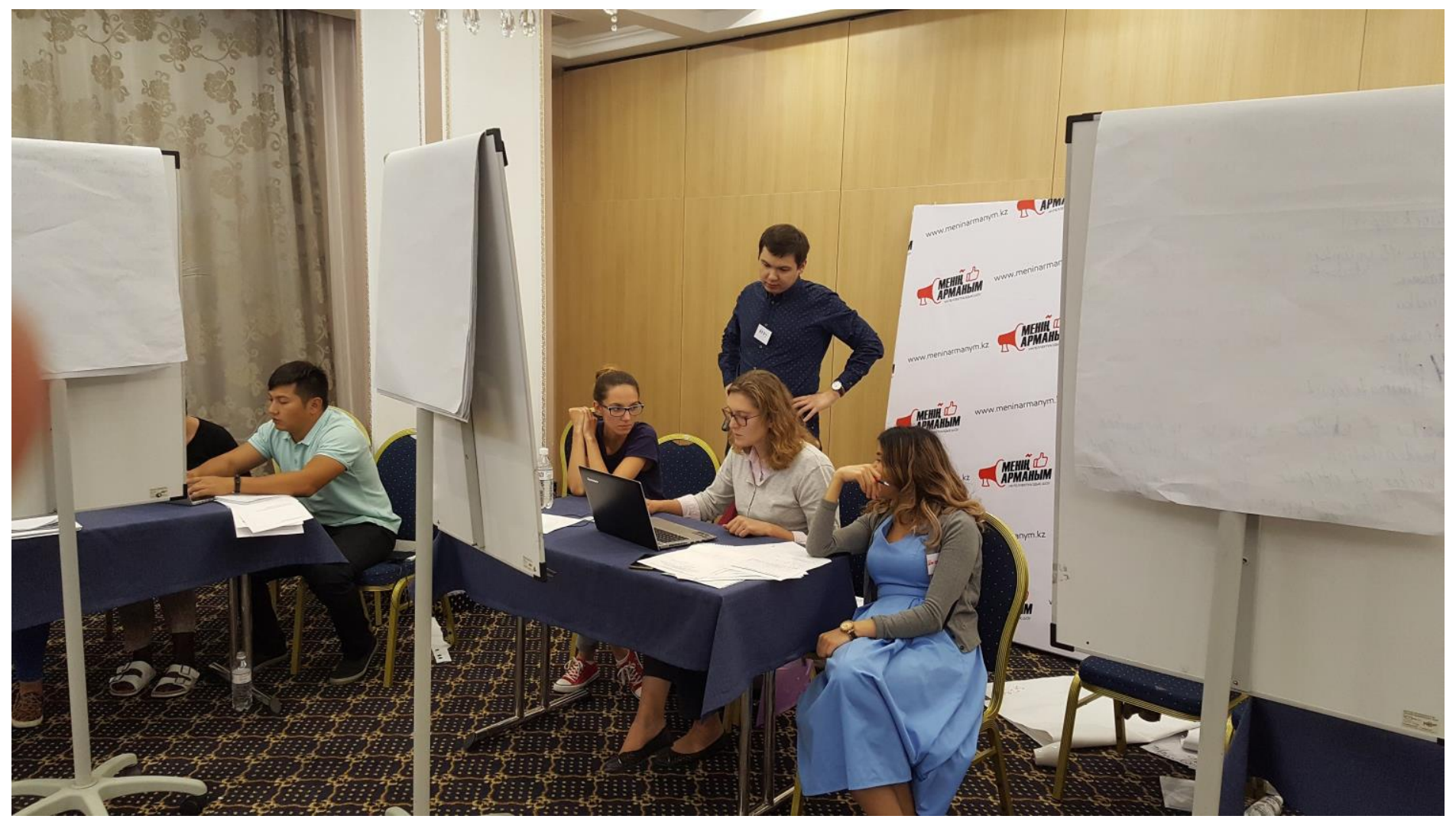

Figure 2. Group Eurasia - storming seriously: Julia Ondrejkova, Abay Bakytzhanuly, Anna Mierzynska, and Umissalima Khassanova

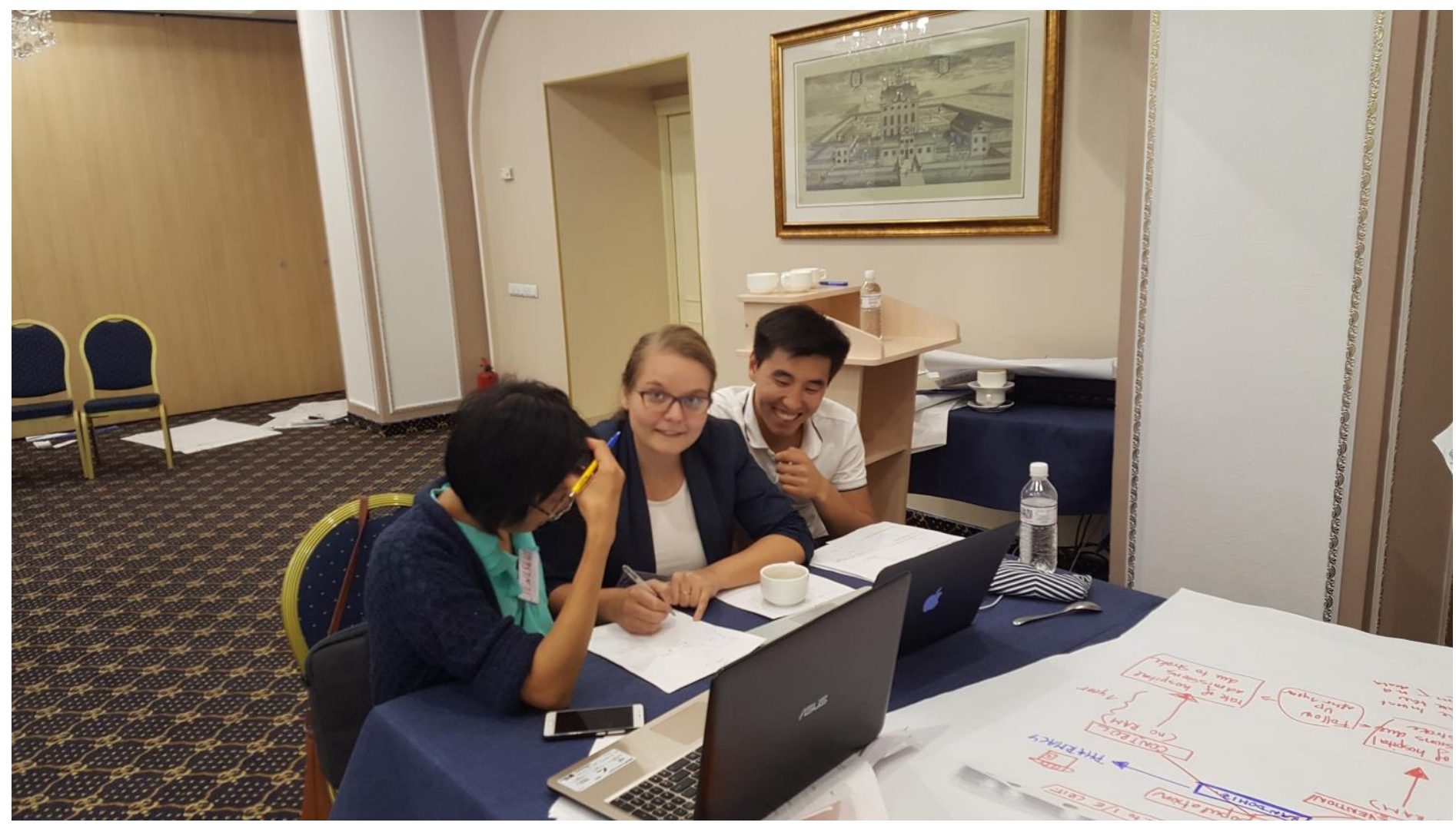

Figure 3. Group K2AfibS - storming cheerfully: Zhenisgul Tlegenova, Zuzana Haramiova and Daniyar Cholponbaev 


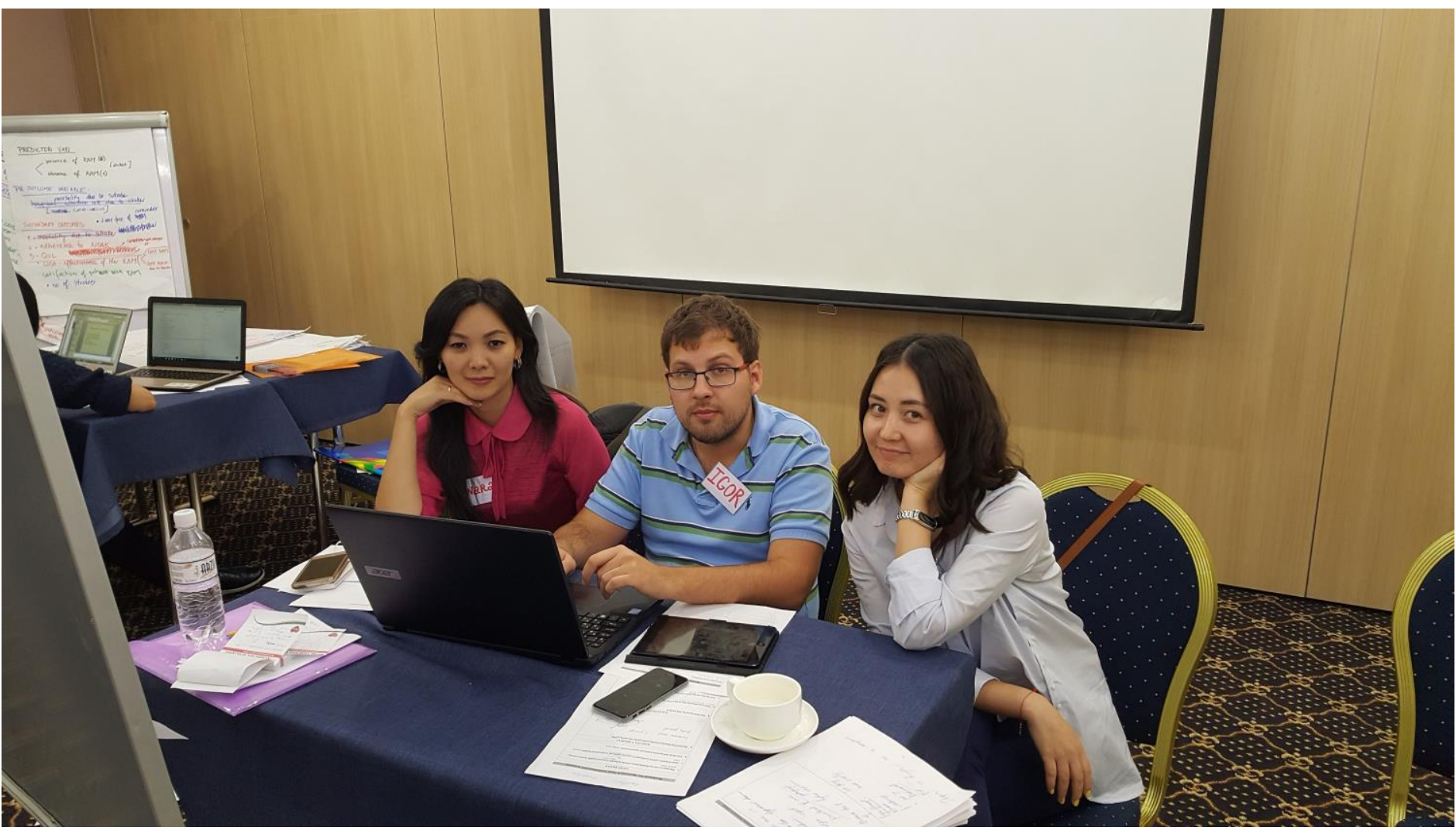

Figure 4. Group Doctor`s House - storming nicely: Dinara Isabaeva, Igor Straka and Aray Zhilkibayeva
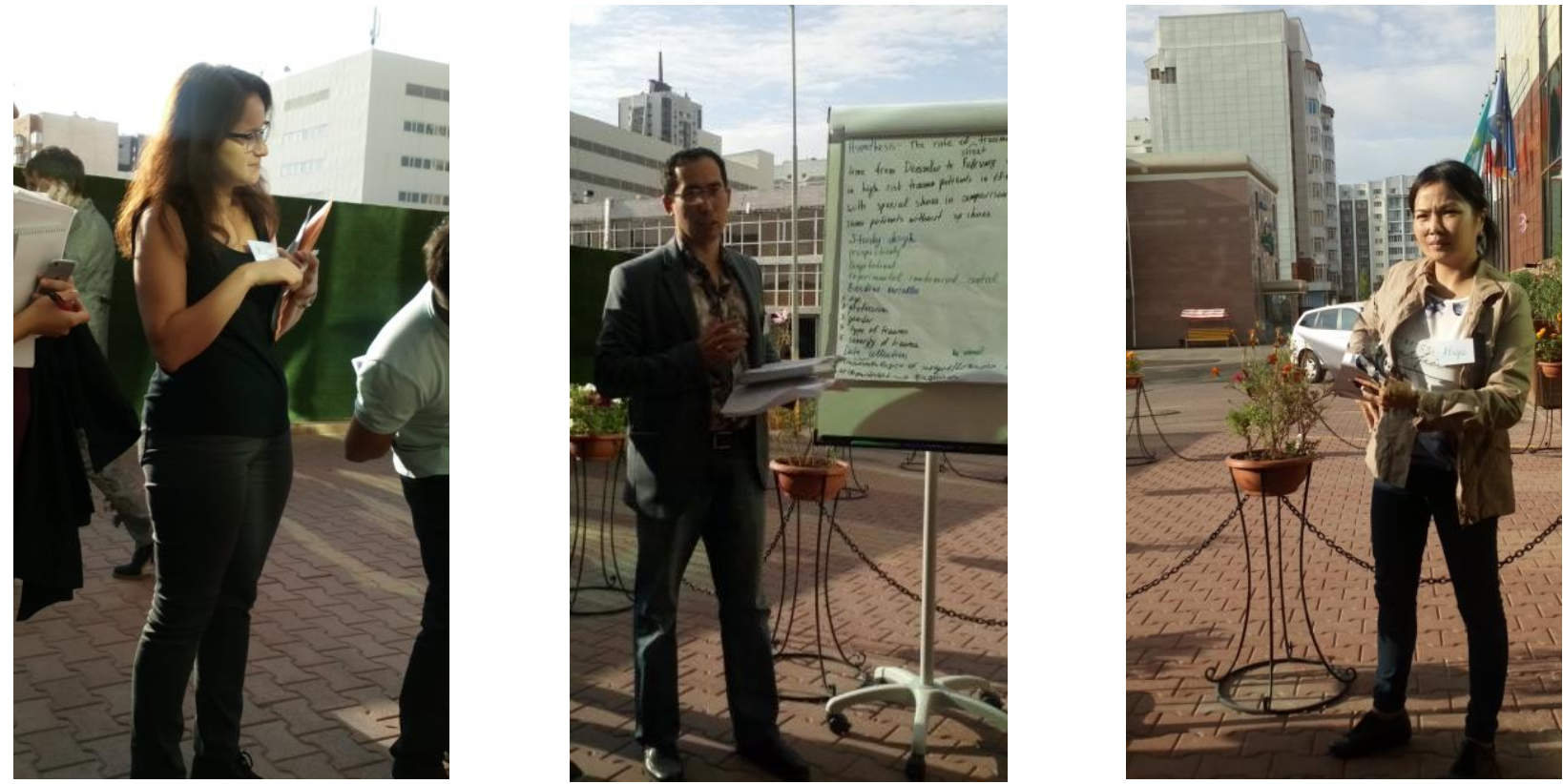

Figure 5. Group Friendship - performing outdoors: Radka Alacova, Arman Mussabekov and Aliya Smagulova 


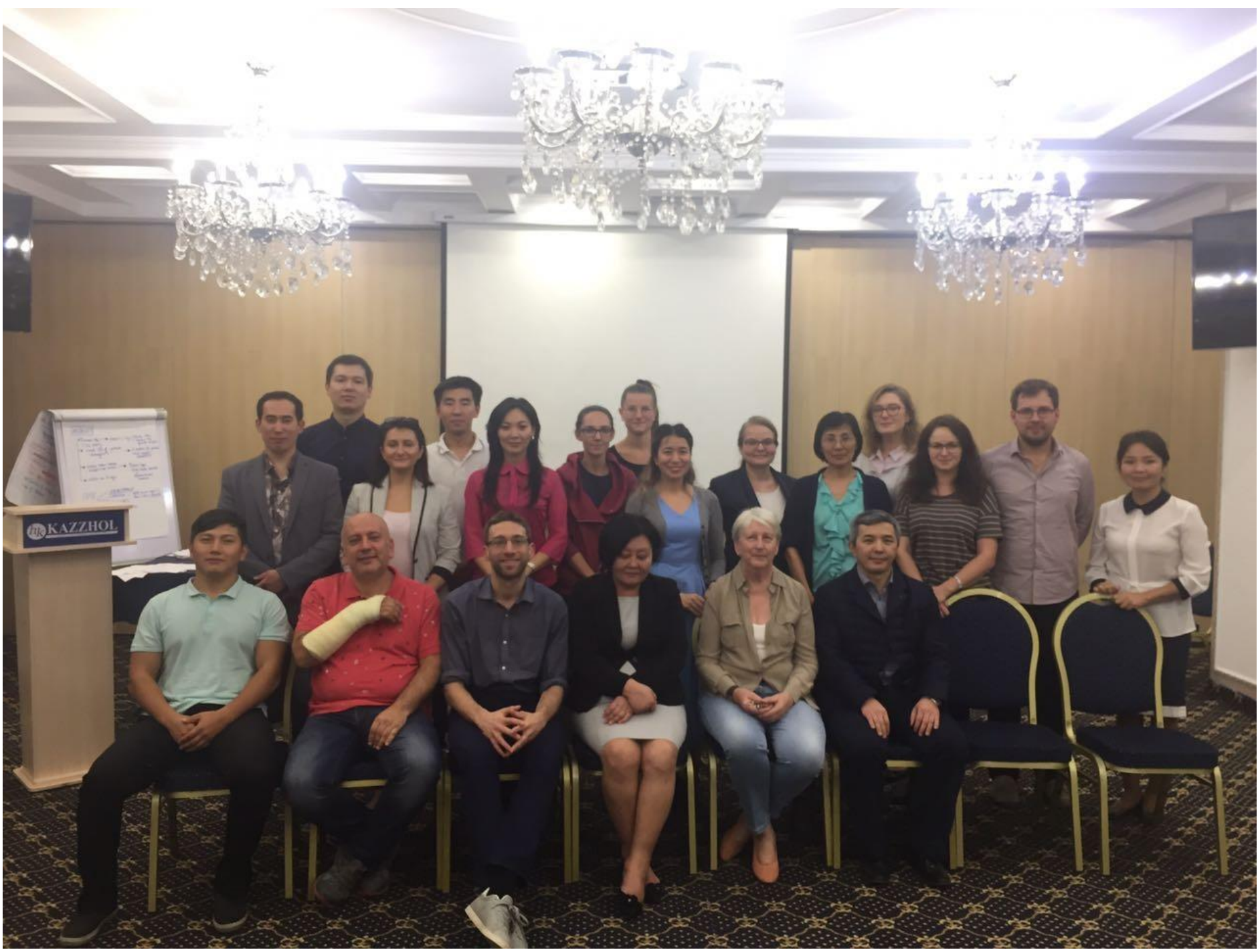

Figure 6. IRIS team group photo after closure ceremony: $1^{\text {st }}$ raw - Kairat Nurbekov, Oben Baysan, Jonathan Lipton, Gulmira Kudaiberdieva, Ljuba Bacharova, Ayan Abdrakhmanov; $2^{\text {nd }}$ raw Arman Mussabekov, Abay Bakytzhanuly, Brigita Benkoova, Daniyar Cholponbaev, Dinara Isabaeva, Julia Ondrejkova, Maria Enoksson, Umissalima Khassanova, Zuzana Haramiova, Zhenisgul Tlegenova, Anna Mierzynska, Radka Alacova, Igor Straka, Aliya Smagulova 


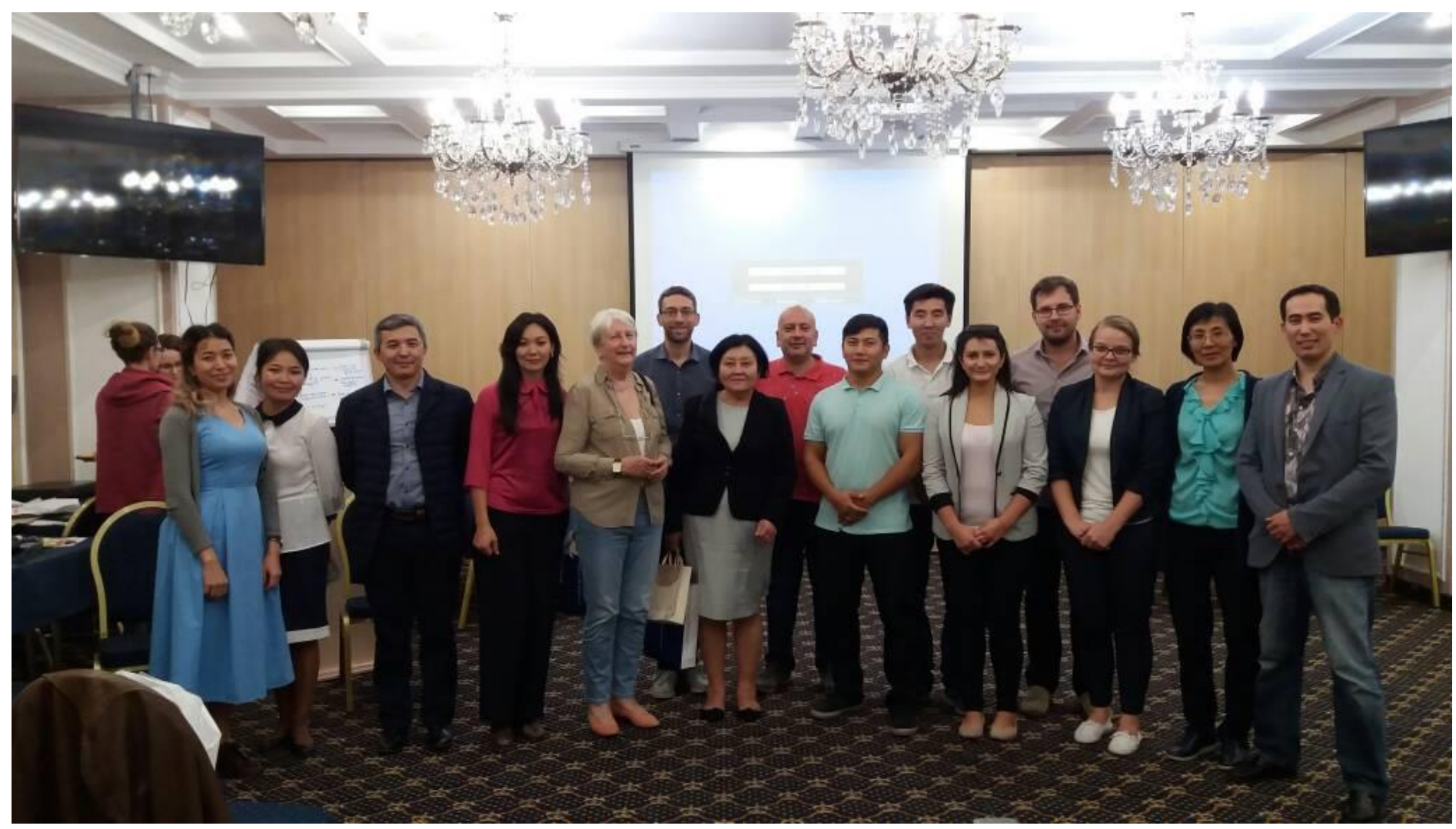

Figure 7. Group photo after closure ceremony: Umissalima Khassanova, Aliya Smagulova, Ayan Abdrakhmanov, Dinara Isabaeva, Ljuba Bacharova, Jonathan Lipton, Gulmira Kudaiberdieva, Oben Baysan, Kairat Nurbekov, Daniyar Cholponbaev, Brigita Benkoova, Igor Straka, Zuzana Haramiova, Zhenisgul Tlegenova, Arman Mussabekov

Peer-review: Internal

Conflict of interest: None to declare

Authorship: O.B., A.A. equally contributed to the preparation of report

Acknowledgement and funding: None to declare

\section{References}

1. Bacharova L, Kudaiberdieva G, Misak A, Hakacova N, Timuralp B, Wagner GS. The effect of International Scientific Summer School research training on scientific productivity of trainees. Int J Cardiol 2014: 176; 1142-6.

2. Marusic A, Marusic M. Teaching students how to read and write science: a mandatory course on scientific research and communication in medicine. Acad Med 2003; 78: 1235-9.
3. Taylor RS, Reeves BC, Ewings PE, Taylor RJ. Critical appraisal skills training for health care professionals: a randomized controlled trial [ISRCTN46272378]. BMC Med Educ 2004; 4: 30.

4. Davis TH, III, Wagner GS, Gleim G, Andolsek KM, Arheden $\mathrm{H}$, Austin $\mathrm{R}$, et al. Problem-based learning of research skills. J Electrocardiol 2006; 39: 120-8. 